\title{
LITERATURA NO JORNALISMO DA REVISTA PIAUÍ
}

\author{
SILVA, Dayane Joyce Lino da ${ }^{1}$ \\ GUIMARÃES, Raquel Beatriz Junqueira ${ }^{2}$
}

RESUMO: Este artigo intenta discutir e analisar aproximações existentes entre literatura e imprensa. Para isso, buscamos manifestações do chamado jornalismo literário nas páginas da revista piauí, demonstrando que as reportagens publicadas nesse periódico subvertem fronteiras em direção ao texto literário. A interlocução entre literatura e imprensa também é presente na piauí por meio da circulação de textos poéticos de diferentes autores, o que contribui para a divulgação da poesia e de poetas contemporâneos.

PALAVRAS-CHAVE: Jornalismo literário, imprensa, poesia, literatura, piauí.

\section{LITERATURE IN PIAUÍ MAGAZINE'S JOURNALISM}

\begin{abstract}
This article intends to discuss and to analyze existing approaches between Literature and the Press. For that, we have looked for manifestations of the so-called literary journalism in the pages of the piaui magazine, demonstrating that the reports published in this periodical subvert boundaries towards the literary text. The dialogue between Literature and the Press is also present in piaui through the propagation of poetic texts by different authors, which contributes to the dissemination of contemporary poetry and poets.
\end{abstract}

KEYWORDS: Literary journalism, press, poetry, literature, piauí.

\footnotetext{
${ }^{1}$ Doutoranda em Literatura e Língua Portuguesa no Programa de Pós-Graduação da Pontifícia Universidade Católica de Minas Gerais. E-mail: dayanejoyce@outlook.com

${ }_{2}^{2}$ Professora Adjunta da Pontifícia Universidade Católica de Minas Gerais. Coordenadora do Centro de Estudos luso-afro-brasileiros. E-mail: raquelbea.junqueira@gmail.com
} 


\section{A CIRCULAÇÃO DA LITERATURA EM JORNAIS E REVISTAS}

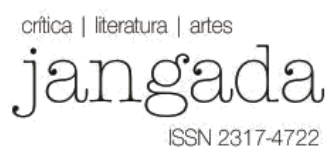

A mim me parece que é mais do que nunca necessária a poesia. Para lembrar aos homens o valor das coisas desimportantes, das coisas gratuitas. (BARROS, 1996, p. 310).

Em conhecida canção popular, Caetano Veloso, em tom de questionamento, cantou: "O sol nas bancas de revista / me enche de alegria e preguiça/ quem lê tanta notícia?" (VELOSO, 1968). A pergunta de Caetano e a afirmação do poeta Manoel de Barros em epígrafe dirigiram nossa atenção para a presença da literatura em ambientes midiáticos diversos.

Exemplo de que os jornais e revistas sempre proporcionaram a circulação da literatura está tanto nos folhetins que circulavam em jornais do século XIX, quanto no século XX, em revistas como Status, O Cruzeiro, Veja, Istoé, Senhor, Manchete, Realidade, Época e piauí que abriram e abrem espaços para os mais diferentes gêneros literários: o conto, a crônica, o poema. Várias dessas revistas já foram objeto de pesquisa tanto sobre divulgação da ciência, de estudos da circulação literária, quanto de relações entre História, Jornalismo e Literatura. A revista $O$ Cruzeiro, por exemplo, tem reconhecida importância na preparação do lançamento da escritora Carolina de Jesus. Vários estudos sobre a autora se referem às edições que prepararam o público para a recepção do seu livro Quarto de despejo. ${ }^{4}$ Outro exemplo de estudos sobre a circulação da literatura na mesma revista é o trabalho de Raquel França dos Santos Ferreira, que se dedica à análise de crônicas de Rachel de Queiróz publicadas na última página daquele semanário. ${ }^{5}$ No caso da revista Status, que publicava contos eróticos, há estudos como o de Sandra Reimão, que analisa a censura no Brasil. ${ }^{6}$ No campo dos estudos da comunicação social, Nicoli Glória De Tassis Guedes (2014) se dedica a estudar o jornalismo como uma forma de narrativa que se apropria das situações cotidianas e dos agentes sociais, transformados via texto

\footnotetext{
${ }^{3}$ O nome Piauí será grafado com inicial minúsculas para manter a forma apresentada na revista.

${ }^{4}$ Destaca-se aqui a obra A vida escrita de Carolina Maria de Jesus, de Elzira Divina Perpétua.

${ }^{5}$ Cf FERREIRA, 2015.

${ }^{6}$ Fala-se aqui da tese de livre docência intitulada Repressão e resistência: censura a livros na ditadura militar, na qual Reimão estuda, em um dos capítulos, a censura aos contos Mister Curitiba, de Dalton Trevisan, e O Cobrador, de Rubem Fonseca, vencedores dos concursos de contos promovidos pela revista Status nos anos de 1976 e 1978, respectivamente.
}

Jangada | nr. 16, jun/dez, 2020 | ISSN 2317-4722 
em acontecimentos e personagens, para discutir as disputas simbólicas que incidem sobre a tarefa de narrar o real. ${ }^{7}$

Destaca-se, aqui, antes de analisar o que ocorre hoje com a piauí, no âmbito das relações do jornalismo com a literatura, o caso da Manchete, semanário que contou com um número expressivo de colaboradores vinculados à atividade literária, o que interferiu nos tons de suas reportagens e nos temas escolhidos para serem noticiados e analisados, principalmente na primeira década de circulação (1952-1962). No semanário circulava uma grande diversidade de matérias sobre literatura e a vida literária no Brasil, algumas em linguagem mais informativa. Na primeira década de existência, a Manchete trazia colunas fixas como "Conversa Literária" e "Poesia Necessária", comandadas por Paulo Mendes Campos. No ano de 1957, circulou pelo semanário uma série de depoimentos nomeada "Escritores falam de sua terra". Nessa série são encontrados 21 textos, cada um representando um estado brasileiro: Alagoas, Amazonas, Bahia, Ceará, Distrito Federal, Espírito Santo, Goiás, Mato Grosso, Maranhão, Minas Gerais, Pará, Paraíba, Paraná, Pernambuco, Piauí, Rio de Janeiro, Rio Grande do Norte, Rio Grande do Sul, Santa Catarina, São Paulo, Sergipe, perfazendo 20 estados e o Distrito Federal. Essas matérias eram todas de caráter subjetivo, em linguagem autobiográfica, um pouco reportagem, um pouco ensaio, levando o leitor da revista para os mais diversos cantos do país. ${ }^{8}$ Como se pode ver, o engajamento jornalístico com a literatura faz parte tanto da história do jornalismo no Brasil quanto da inserção social e cultural da própria literatura brasileira e de seus escritores.

Em diversas edições de Manchete podem ser encontrados depoimentos de escritores como Fernando Sabino, Graciliano Ramos, Manuel Bandeira, Vinícius de Moraes, crônicas de Rubem Braga, Carlos Drummond de Andrade, Henrique Pongetti. Há, também, discussões teóricas sobre a recepção literária e as novas formas do romance, num evidente trabalho de literatura e sobre literatura.

Vejamos mais um exemplo: Carlos Alberto Tenório publicou uma reportagem intitulada “Onde estão os poetas". Nela, desde o início, pode-se notar a tentativa do jornalista de humanizar a figura do poeta:

A presente reportagem é menos para os homens de letras - poetas, críticos e professores da Arte Poética - que para o público que lê e gosta de poesia. Pode sugerir uma distinção pretensiosa traçar-se o caminho de uma reportagem de

\footnotetext{
${ }^{7}$ Refere-se ao estudo Três modos de ser revista: Jornalismo e cotidiano em O Cruzeiro, Realidade e Piauí.

${ }^{8}$ Para conhecer mais sobre a presença da literatura na revista Manchete cf. GUIMARÃES, 2013.
} 
revista, pensando em um público determinado e certo. Não é bem isso. Porque os primeiros, ao descobrirem, no corpo da publicação, a fotografia do perfil de Capeto do poeta Bandeira ou a figura rubicunda do Sr. Frederico Schmidt, o ar mítico do Sr. Jorge de Lima, o aspecto seminarista de Carlos Drummond ou a fisionomia simpática do poeta Vinícius, decerto quererão revê-los. Há coisas velhas, coisas publicadas, coisas conhecidas e lidas. Isto não preocupa porque não há pretensão de inédito, nem piadas, nem jogo de palavras, ou entrevistas cujas respostas irônicas e bem articuladas produzam um bom efeito. $O$ que se deseja é contar ao público alguma coisa sobre a vida dos poetas e que seja explicado em reportagem o fenômeno poético modernista. (TENÓRIO, 1952, p. 11. Grifo nosso)

De acordo com Tenório, nesses depoimentos os escritores procuram explicar ao público o que os faz ser considerados herméticos. Formulam hipóteses e apresentam justificativas sobre o motivo pelo qual o grande público estranhou a poesia moderna. São, portanto, formas de teorizar a recepção da produção literária daquela época, numa tentativa de “explicar o fenômeno poético modernista" (Tenório, 1952, p. 11), intenção explícita da matéria. Assim, ainda que com um caráter didático, o jornalista procura aproximar o poeta do público leitor, aquele que gosta de poesia. Tenório procura construir a imagem dos escritores como sujeitos comuns. Isso pode ser verificado nas fotos que acompanham a reportagem: Manuel Bandeira de pijama e na cozinha; Augusto Frederico Schmidt ao telefone; e Jorge de Lima num atendimento médico.

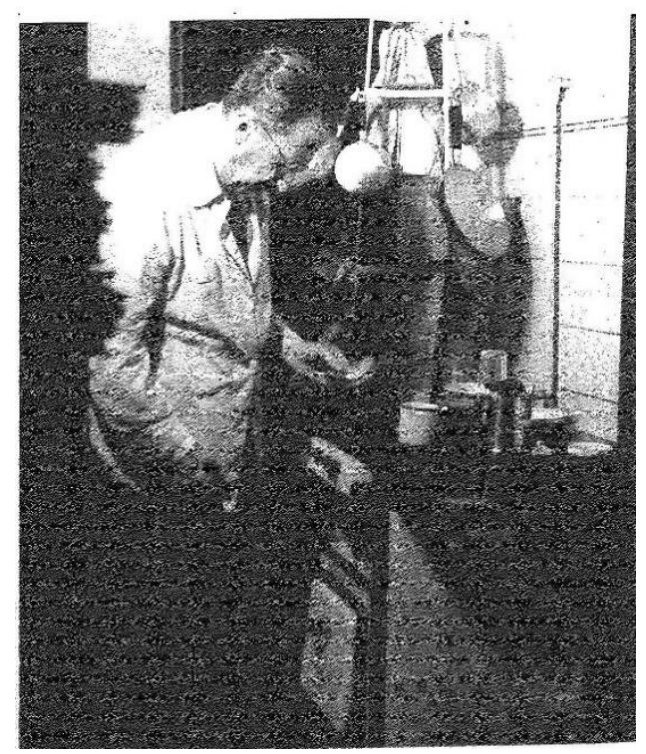

FIGURA 1 - Foto de Manuel Bandeira

Fonte: Revista Manchete. TENÓRIO, 1952, p. 11 


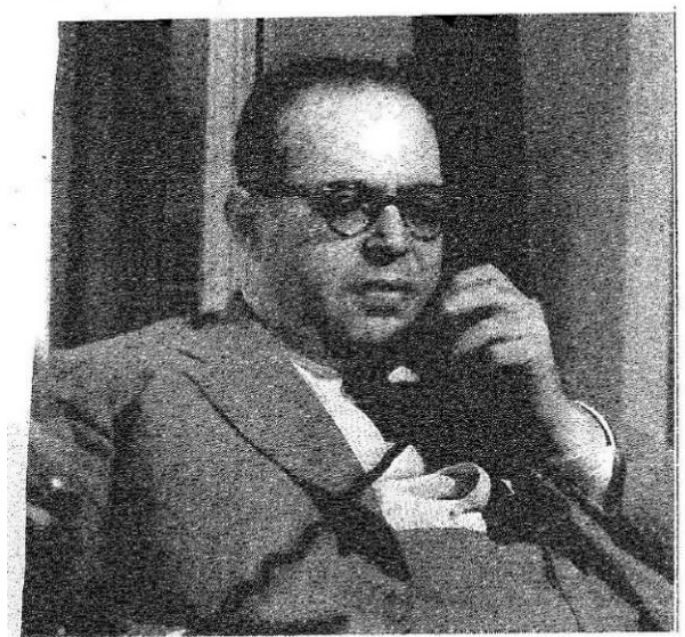

aUGUSTO FREDERICO SCHMIDT

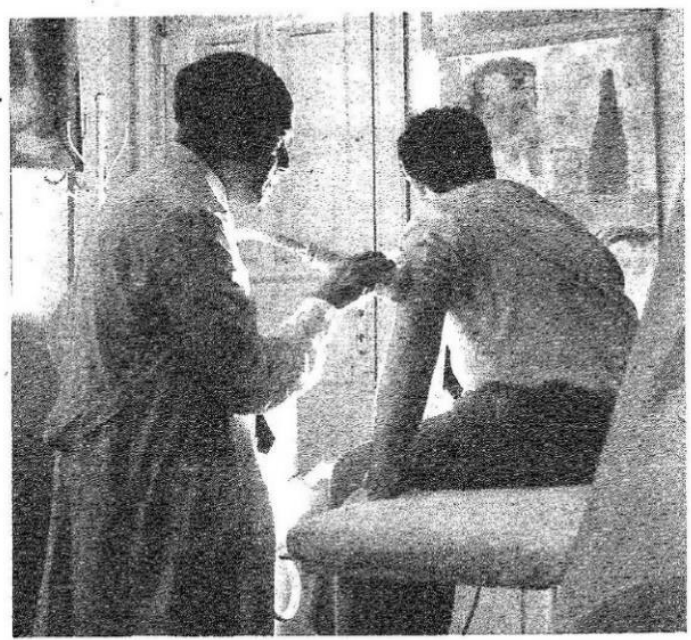

JORGE DE UIMA

FIGURA 2 - Fotos de Augusto Frederico Schmidt e Jorge de Lima Fonte: Revista Manchete. TENÓRIO, 1952, p.11

Essa aproximação histórica e cultural entre literatura e jornalismo nos faz pensar no sentido da expressão “jornalismo literário". Antes, porém, de discutirmos especificamente a noção de jornalismo literário, é preciso lembrar que há vários modos de a literatura aparecer em publicações jornalísticas: por meio da publicação de textos literários em ambientes jornalísticas, por matérias como essa de Tenório, que trata de questões de arte, cultura e especificamente de literatura, e por reportagens que são escritas de modo que procura se afastar do especificamente jornalístico e do especificamente literário.

Vilas Boas (2007) pensa que jornalismo literário seria, “o casamento verdadeiramente íntimo entre o J (Jornalismo) e o L (Literatura), algo há muito tempo praticado e apreciado pelo público, mas talvez esquecido pela crítica" (VILAS BOAS, 2007, p. 20). Ainda de acordo com Vilas Boas, o jornalismo literário "foge das fórmulas rígidas de estruturação. Suas referências narrativas (procedimento e técnica) vêm da literatura" (VILAS BOAS, 2007, p. 10). A partir das reflexões do autor, parece possível afirmarmos que o jornalismo literário é uma possibilidade de produção que ultrapassa os aparentes limites do jornalismo.

A linguagem trabalhada no jornalismo literário abre espaço para novas perspectivas que se pode tirar de um fato, e essas novas perceptivas possibilitam "juntar os elementos presentes em dois gêneros diferentes, transforma-os permanentemente em seus domínios 
específicos, além de formar um terceiro gênero, que também segue pelo inevitável caminho da infinita metamorfose" (PENA, 2006, p. 10).

Os dizeres de Pena reafirmam a noção, com a qual compartilhamos, de que o jornalismo literário é uma junção de dois domínios e é, ao mesmo tempo, a constituição de um terceiro. Isso porque, ainda segundo Pena, "não se trata da dicotomia ficção ou verdade, mas sim de uma verossimilhança possível. Não se trata da oposição entre informar ou entreter, mas sim de uma atitude narrativa em que ambos estão misturados. Não se trata nem de jornalismo, nem de literatura, mas sim de melodia" (PENA, 2006, p. 13). Dessa forma, o jornalismo literário pode ser entendido como um conjunto de estratégias de produção textual de domínios diferentes, esse conjunto de estratégias possibilita aos leitores experiência de leitura que difere da experiência possibilitada pela grande mídia, sem ignorar os paradigmas do jornalismo diário. Assim, o que o jornalismo literário faz é "desenvolver estratégias já conhecidas, de maneira que acaba criando novas estratégias" (PENA, 2006, p. 13). Para ele, o próprio conceito de jornalismo literário

é caracterizado como uma modalidade de prática da reportagem de profundidade e do ensaio jornalístico utilizando recursos de observação e redação originários da (ou inspirados pela) Literatura. Traços básicos: imersão do repórter na realidade, voz autoral, estilo, precisão de dados e informações, uso de símbolos (inclusive metáforas), digressão e humanização. (PENA, 2006, p. 105).

Os estudos das práticas de aproximação entre jornalismo e literatura indicam que a procura por formas que as consolidam não é recente e ao longo da história já receberam vários nomes: "prática muckraking, new journalism, jornalismo-literário, livro-reportagem, romance de não ficção, etc.” (RITTER, 2013, p. 67).

Um dos principais representantes dessa prática jornalística que busca construir narrativas esteticamente muito mais próxima da literatura é o movimento que teve início nos Estados Unidos, na década de 1960, e como principais expoentes Tom Wolfe, Gay Talese, Norman Mailer e Truman Capote: o new journalism.

Os novos jornalistas buscavam ir até a notícia, esmiuçá-la, ver o mais de perto possível, para transmitir ao leitor, não só os fatos, mas também as suas 
impressões, suas emoções, bem como as impressões e as emoções dos personagens. (RITTER, 2013, p. 64).

Tom Wolfe (2005) definiu quatro recursos fundamentais para a prática do new journalism:

O primeiro, e mais básico desses recursos, é a necessidade de se contar a história cena a cena, ou seja, passando o enredo de quadro a quadro sem recorrer tanto à narrativa histórica. Para isso, o autor destaca que é necessário desenvolver o segundo recurso básico: o registro dos diálogos completos, pois, "o diálogo realista envolve o leitor mais completamente do que qualquer outro recurso" [...] O terceiro recurso é o já citado ponto de vista da terceira pessoa, apresentando cada cena ao leitor por intermédio de um personagem, "dando ao leitor a sensação de estar dentro da cabeça do personagem, experimentando a realidade emocional da cena como o personagem experimenta." (WOLFE, 2005, p. 54).

O último recurso citado pelo autor é o registro de gestos, hábitos, maneiras, costumes, estilos de mobília, roupas, decorações, maneiras de viajar, comer, manter a casa, modo de se comportar com os filhos, com os criados, com os superiores, com os inferiores, com os pares, além de olhares, poses, estilos de andar e qualquer outro elemento simbólico do cotidiano que possa existir dentro da cena narrada. (WOLFE, 2005, p. 55).

Embora possamos pensar de outro modo, que jornalismo literário é, de maneira mais ampla, uma iniciativa jornalística de fazer circular a literatura, seja na forma, seja no seu conteúdo, não deixamos de acompanhar os estudiosos que desenvolvem as reflexões sobre as noções segundo as quais “o jornalismo-literário é (...) a utilização dos métodos de reportar (Jornalísticos) e as técnicas de expressão (Literária)" (VILAS BOAS, 2007, p. 20). Com essa percepção, voltamo-nos para a revista piauí.

Apresentaremos três reportagens para exemplificar como na piauí o modo de narrar um fato/história “cumpre a missão de informar, preservando a essência jornalística, porém com ganho em vocabulário, estrutura narrativa e aprofundamento de conteúdo" (WEISE, 2013). 


\section{O CASO DA REVISTA PIAUÍ}

A piauí é uma revista mensal idealizada pelo empresário, documentarista, roteirista e produtor de cinema brasileiro João Moreira Salles. Lançada em julho de 2006, a publicação chegou até as bancas em outubro do mesmo ano. Ao contrário da maioria das revistas, as publicações da piauí não são pautadas pelos acontecimentos "quentes", ou seja, não são trabalhadas notícias urgentes, factuais. De acordo com o idealizador do periódico: "não haveria sentido em criar mais uma revista para cobrir as mesmíssimas histórias. [...] cobrimos assuntos que interessam, mas sem pressa, publicando meses depois, ou de forma diferente." (SALLES, 2015)

Em outra oportunidade, João Moreira Salles afirmou que o "luxo" da piauí é o tempo: "há várias matérias que são feitas ao longo de três meses. Isso não existe na imprensa brasileira - uma imprensa com pressa, pressa de chegar antes, de dar a notícia primeiro. A piauí tem o luxo de ser lenta" (SALLES, 2012). A partir dessa afirmação, parece possível afirmarmos que a piauí não opera com fórmulas ou padrões que acelerem a produção do texto jornalístico para acompanhar a rapidez dos fatos. Ao contrário, seus colaboradores usufruem de liberdade de tempo para poderem elaborar reportagens de maior fôlego nas quais podem usar recursos narrativos e linguísticos mais elaborados e, por vezes, mais sofisticados. Contam, também, com a autonomia para sugerir pautas. Essas e outras "liberdades" não são encontradas no jornalismo impresso tradicional.

Como a piauí não comporta publicações fixas, não trata dos mesmos temas em todas as edições. As únicas seções presentes desde a primeira edição são: chegada, esquina e despedida. A revista cria novas seções a cada publicação, pois "a graça da piauí é que ela é quase inventada do zero a cada número" (SALLES, 2015). Não há restrições temáticas e não há territórios demarcados por colunistas: os colaboradores têm liberdade para sugerir pautas, já que o importante na piauí é uma boa história, bem narrada. Segundo o Mídia Kit divulgado em comemoração aos dois anos de existência da revista: "publicamos para quem gosta de ler. Vale praticamente qualquer tema. Política, literatura, economia, televisão, arquitetura, cinema, futebol, odontologia - contanto que o dentista seja interessante, ou o tratamento de canal, revolucionário" (PIAUÍ, 2019, p. 2).

Com a proposta de criar uma revista com perfil editorial diferenciado, a piauí mantém entre seus colaboradores jornalistas, escritores, artistas gráficos, ensaístas, críticos e humoristas, 


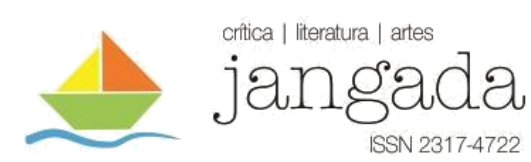

possibilitando aos leitores da publicação mensal "a mistura incomum de reportagens políticas com histórias em quadrinhos, revelações do mundo econômico com poesia, perfis de esportistas com tolices bem-humoradas" (PIAUÍ, 2019, p. 8).

Considerando esses dados sobre o perfil da revista, podemos afirmar que a prática jornalística da piauí é, no mínimo, diferenciada em relação a outros periódicos da imprensa brasileira. Salles propicia um espaço que pode ser de todos: trata-se de um espaço que abriga diversos gêneros e no qual tudo entra, tudo é válido. Com isso, a piauí experimenta grandes temas e manifesta-se atenta a seu tempo.

É nesse contexto, sem atrasos, e com espaço próprio, que a poesia chega às páginas da revista, na seção nomeada, justamente, de poesia, na qual encontramos e reencontramos poetas contemporâneos, que colocam o próprio tempo em diálogo com os outros tempos. Poetas que "mantêm fixo o olhar no seu tempo, para nele perceber não as luzes, mas o escuro" (AGAMBEN, 2009, p. 59) e que estabelecem "uma singular relação com o próprio tempo, que adere a este e, ao mesmo tempo, dele toma distâncias" (AGAMBEN, 2009, p. 65); artistas que fazem do inconformismo e da assincronia um modo de relação com seu tempo.

O mineiro Ricardo Aleixo é um desses poetas que estabelecem singular relação com seu tempo. Nas páginas da piauí, marca tensões e ambiguidades ao expressar "A força muda do meu[seu] grito" (ALEIXO, 2020a), em poemas publicados na edição 167, de agosto de 2020: “Conforme o acaso" (ALEIXO, 2020b), “Quando soa a nossa voz” (ALEIXO, 2020c), "Minhas coisas favoritas" (ALEIXO, 2020d):

Acordou-me a força/ do meu próprio grito/mudo, eu/numa espécie/de galeria de espelhos/em meio a pilhas/de corpos negros/que algum/brusco movimento/do mar deslocou/até o fundo/do meu sonho/Não sei bem/se acordei de fato/nem se a palavra/acorda/aplica-se a um caso/como o desta/tentativa de poema/mas registro que/era real - ainda/vibra - a tal/força muda/do meu grito. (ALEIXO, 2020a). 
A FORÇA MUDA DO MEU GRITO

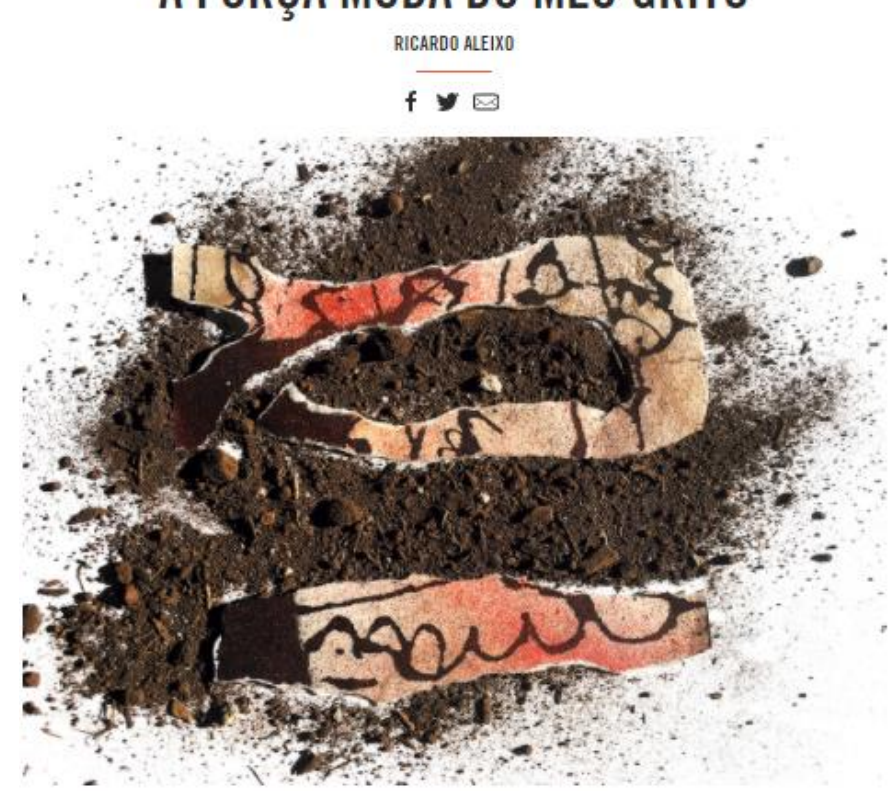

FIGURA 3 - Ilustração da seção poesia. Fonte: Revista piauí. ALEIXO, 2020e.

Também mineiros, Edimilson de Almeida Pereira e Ana Martins Marques compartilharam suas artesanias com a linguagem junto aos leitores do periódico. Pereira, com "Roda-viva" (PEREIRA, 2019d), "De volta ao sol" (PEREIRA, 2019a) e "Jam Session" (PEREIRA, 2019c), alerta-nos de que "Há um sinal na testa de quem não contesta" (PEREIRA, 2019b). Marques surge para suscitar questões de ordem metalinguística: "É materna a língua em que se silencia/ (por isso o silêncio apresenta problemas bastantes específicos/ para a tradução) / só me calo/ em português" (MARQUES, 2019). A autora parece trazer aos leitores da piauí outro mineiro, Drummond, ao apresentar em seu caminho poético uma palavra-pedra: “Às vezes me ocorre encontrar uma palavra/ enganchada a uma lembrança/ como uma lâmpada num bocal/ um poema não é mais/ do que uma pedra que grita.” (MARQUES, 2019)

Ao pensar sobre a poesia dentro da própria poesia, ao falar sobre seu próprio labor estético, ao discutir concepções sobre o ser poeta, Laura Liuzzi inscreve seus versos na piauí: "Todo poema/ tem tudo aquilo que não diz/ ou seja: tudo/ quando escrevo este poema/ ou qualquer outro eu escrevo/ sobre tudo o que não sei dizer. (LIUZZI, 2010)" Felipe Fortuna, "farto do lirismo comedido/ do lirismo bem-comportado" (BANDEIRA, 2000, p. 6), dispõe seu cordel inventivo, diferenciado e irreverente, na publicação de Salles: "Leitor prezado que agora/ começa a ler meu relato:/ peço atenção e silêncio/ para que, sem muito ornato, / eu possa escrever com rimas/ um enredo que me anima/ pois é fato e não boato.” (FORTUNA, 2019) 
Abordando o cotidiano e o amor, seja em versos livres ou em forma de soneto, Gregório Duvivier, antes de levar a público seu segundo livro de poesias, Ligue os pontos poemas de amor e big bang (2013), publicou alguns dos textos poéticos que compõem essa obra nas páginas da revista piauí. Esse movimento de Duvivier não é novo, pois escritores como Machado de Assis, José de Alencar, Fernando Sabino, Carlos Drummond de Andrade, por exemplo, já haviam feito das páginas de jornais e revistas um espaço privilegiado para o ineditismo de suas obras. Esse expediente foi usado por inúmeros escritores, o que possibilita que os autores fazem e sempre fizeram da imprensa um espaço de circulação da criação poética, tal como faz Duvivier na piauí

Se eu fosse um faraó do Egito antigo/ não me faria falta o carnaval do Rio/ o ipod o iphonel [...] a única invenção cuja inexistência/ me obrigaria a tomar o cianureto/ mais em voga das maravilhas do mundo/ moderno a única que me faria falta/ é você (e talvez quem sabe o ar condicionado, mas sobretudo você. (DUVIVIER, 2013).

Os poetas referidos aqui são apenas alguns dos que encontramos ao percorrermos as páginas da revista piauí. Nesse sentido, a piauí, ao reservar um espaço para a literatura, traduzse como vetor de numerosos poemas e, tal como jornais e revistas dos séculos XIX e XX, contribui para fazer circular a arte literária e os acontecimentos da vida literária no Brasil.

Avançando na discussão, objetivamos demonstrar que, para além de fazer circular o texto literário, a revista apresenta reportagens cujos textos são elaborados de maneira mais próxima da escrita literária. Na piauí, forma e conteúdo são "parceiros da mesma aventura, assim como são na boa literatura de ficção" (VILAS BOAS, 2007, p. 24). O que importa não é apenas o que é dito, mas o como é dito. Nesse sentido, João Moreira Salles afirma que

[a] matéria que dá certo na revista é aquela sobre um assunto em que o leitor não tem, de antemão, interesse. Ele começa a ler e aí é a narrativa, a estrutura que faz com que ele chegue ao final tendo lido alguma coisa que ele não sabia que podia ser interessante. Quando isso acontece, a gente acerta. (SALLES, 2015).

$\mathrm{Na}$ piauí, a estrutura narrativa tem importância, o fato bruto é trabalhado e "transforma-se em reportagem por meio da narração fluente" (AMARAL,1986, p. 133) a fim 
de "expor os fatos de maneira que o leitor se sinta atraído do princípio ao fim do texto" (AMARAL,1986, p. 133). Muitas características encontradas nas formas das reportagens da piauí apontam para a narrativa jornalístico-literária, apesar de João Moreira Salles nunca ter ressaltado a escolha desse gênero. Para o idealizador da revista, "existe bom jornalismo e mau jornalismo. Só. Jornalismo literário é um nome pomposo, que quer se aproximar da eternidade da literatura. Pretensão de ser algo maior que eu não acho maior” (SALLES, 2007). Entendese, no entanto, que é impossível negar que "o jornalista opera nos limites do escritor, na medida em que ambos lidam com a força comunicativa da palavra escrita” (LUCAS, 2007, p. 11).

Após a leitura de diversas reportagens, escolhemos as três que consideramos mais significativas para exemplificar essa aproximação estético-formal do texto jornalístico da revista com recursos próprios do trabalho literário. O primeiro texto analisado é "A última viagem", de Ricardo Gallo, publicado na edição 101, de fevereiro de 2015. A segunda reportagem, "A bancada de um homem só", de Adriana Abujamra, foi publicada na edição 110, de novembro de 2015. Por fim, analisamos "O julgamento de Jararaca", texto da repórter Adriana Negreiros, publicado edição 130, de julho de 2017.

Partimos da compreensão de Luiz Amaral, para quem a reportagem é

[a] representação de um fato ou acontecimento enriquecida pela capacidade intelectual, observação atenta, sensibilidade, criatividade e narração fluente do autor. Trata-se de uma especialidade a meio caminho entre o jornalismo e a literatura ou já dentro dos limites da literatura (AMARAL, 1986, p. 133).

A reportagem é um gênero especial para o jornalismo literário, pois parte de investigação e de apuração dos fatos, preservando a essência jornalística, porém utiliza, para informar, uma estrutura narrativa elaborada e profunda. A reportagem traz consigo não só o fato, mas também uma história. Ainda discutindo o conceito de reportagem, Amaral (1986) acrescenta: "reportagem exige talento, sensibilidade, narração fluente e criatividade. Permite alguma fantasia, mas nunca alheamento aos fatos. Como todo e qualquer material jornalístico, seu compromisso é com a verdade" (AMARAL, 1986, p. 136).

Esse parece ser o caminho trilhado pelas reportagens da revista piauí, pois aprofundam o fato narrado para além da visão precisa e objetiva que outros veículos impressos de comunicação têm demonstrado. Para nós, um bom exemplo da união entre jornalismo e literatura está na reportagem "A última viagem" (2015), que conta sobre a chegada, a fuga e a 


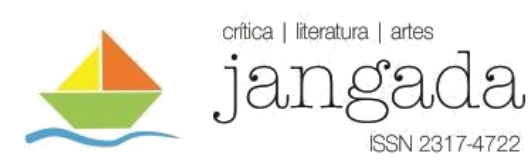

prisão do brasileiro Marco Archer, condenado por tráfico de drogas e executado na Indonésia. Esse acontecimento foi amplamente divulgado pela mídia, ganhando reportagens em diferentes revistas e jornais impressos. O jornalismo convencional reporta $\mathrm{o}$ fato a partir da contextualização dos acontecimentos, fornecendo dados técnicos do ato ilícito praticado por Archer, como a quantidade de drogas transportadas e as circunstâncias em que ele foi preso. Geralmente as reportagens apresentam também uma breve biografia do preso e depoimentos de familiares e amigos. Em seguida, tratam das questões diplomáticas entre os dois países, destacando o pedido de libertação do brasileiro feito pela então presidenta Dilma Rousseff, informando os leitores sobre algumas regras do direito internacional, até chegarem ao desfecho do fato narrado: a execução de Archer.

Em contrapartida, a piauí aborda esse fato noticioso de modo totalmente diferenciado, invertendo o caminho óbvio de contextualização dos fatos ao fazer um recorte preciso na história de Archer, aproximando o texto dos contos de suspense, deixando um final enigmático.

Ricardo Gallo, organiza seu texto em torno da fuga de Marco Archer durante quatorze dias por regiões inóspitas da Indonésia. Gallo edifica uma narrativa que repassa ao leitor os momentos agônicos do fugitivo. Nessa reportagem encontramos uma história real com qualidade estética: o autor narra acontecimentos paralelos, faz uso dos recursos prolépticos e analépticos que, a partir da perspectiva narratológica, considerando os estudos do crítico francês e teórico da literatura Gérard Genette, são, respectivamente, antecipações no tempo, que permitem a anteposição de um fato que só será narrado, no texto, posteriormente, e recuos no tempo, recuperando fatos já passados. Enumera cenas, reproduz diálogos, descreve detalhadamente os ambientes e foge da objetividade ao narrar os sentimentos de Archer, que se torna personagem. $\mathrm{O}$ foco narrativo da reportagem é diferenciado, pois ao invés de reportar com objetividade e distanciamento, Gallo elege um narrador com feições de onisciência:

Começou então o "sofrimento" de Marco, como ele próprio definiria mais tarde. O brasileiro precisava ganhar tempo. Olhou para os policiais e fez sinal de que o passaporte estava numa das malas e que iria buscá-lo. Era mentira: estava em seu bolso. Marco sabia exatamente o que o esperava, caso fosse preso: traficantes são punidos com a morte por fuzilamento, em campo aberto e isolado, a que poucos têm acesso. Enquanto caminhava, o brasileiro observava três dos policiais que saíam em busca de ferramentas para abrir os tubos. Apenas um deles ficou para vigiá-lo e, por um segundo, o homem lhe 
deu as costas. Chegara a hora. Ele olhou para os lados e começou a andar em rápidas passadas. Sem que o policial percebesse, tomou a decisão mais ousada e improvável: fugir. A fuga seria penosa, mas nem lhe passou pela cabeça desistir. Ele teria de fazer um grande esforço para andar rápido, pois não conseguia correr. (GALLO, 2015, p. 51).

Quatro dias se passaram, e Marco/John Miller elaborou um novo plano de fuga. Decidiu aproveitar-se da geografia singular do país - um emaranhado de ilhas entre os oceanos Índico e Pacífico - para escapar da polícia. Seu objetivo era, saltando de ilha em ilha, rumo ao sul, alcançar o Timor Leste, nação que até 2002 era colônia da Indonésia e, mais importante, onde o português é língua corrente. Só que o Timor Leste ficava a cerca de mil quilômetros de distância de onde Marco estava. Para chegar até lá, precisaria atravessar as ilhas de Lombok, Sumbawa e Sumba, em uma escapada que deveria durar algumas semanas. (GALLO, 2015, p. 53)

Os trechos selecionados nos fazem crer que o texto de Gallo transpõe os limites do texto jornalístico exclusivamente noticioso, assemelhando-o, na forma de construção do enredo, de um texto ficcional que procura certa verossimilhança. Isso se percebe com a tentativa do jornalista de aproximar o leitor do ponto de vista do personagem de sua matéria como em: “O brasileiro precisava ganhar tempo. Olhou para os policiais e fez sinal de que o passaporte estava numa das malas e que iria buscá-lo. Era mentira: estava em seu bolso. Marco sabia exatamente o que o esperava, caso fosse preso". A cadência e a sequência narrativa procuram, a nosso ver, conciliar os "métodos de reportar" com as técnicas de expressão. E ainda parece ser uma tentativa de transmitir aos leitores, mais do que os fatos. Uma procura de destacar as emoções dos personagens.

Passemos para a reportagem "A bancada de um homem só" (2015), de Adriana Abujamra. Nela o que está em cena é o cotidiano do parlamentar Jean Wyllys. 


\section{A BANCADA DE UM HOMEM SÓ}

0 únioo deputado federal assumidamente homossexual do país tenta fazer frente à pauta oonservadora do Congresso e sofre oobranọas do movimento gay

ADRIANA ABUJAMRA

$f y \square$

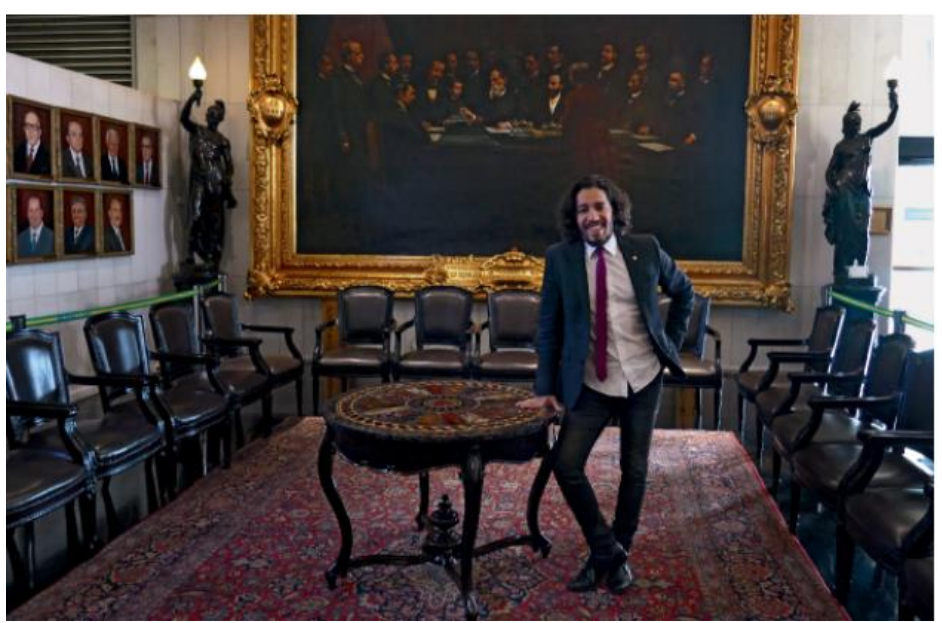

FIGURA 5 - Foto de Jean Wyllys no Congresso

Fonte: Revista piauí. BRITO, 2015.

O início da narrativa é construído de forma muito singular, afastando-se da sumarização e projetando no texto uma série de imagens, como podemos observar no trecho abaixo:

Na manhã do último dia 6 de agosto, numa sala lotada do Senado Federal, uma senhora orava, concentrada. Perto dela, duas moças - os cabelos compridos, as saias na altura dos tornozelos e um terço nas mãos - se dividiam entre orações, sorrisos e cochichos. Rapazes de terno e gravata brandiam cartazes com a imagem de um bebê sorridente e a mensagem: "Brasil vivo! Sem aborto!" Um garoto vibrava como se estivesse num estádio de futebol. (ABUJAMRA, 2015, p. 32)

Por meio da descrição de ambientes e dos jogos de cenas, a visão da reportagem tornase ampla. O texto também promove o acesso do leitor às nuances da personalidade de Jean Wyllys, seus gestos, seus olhares, suas poses e o modo como se comporta em determinadas situações. O olhar de Abujamra é marcado pela subjetividade; o perfilado está humanizado, já que a reportagem apresenta-o não como fonte de informações, e sim como "pessoa", personagem da narrativa. A voz de Wyllys perpassa todo o texto, e assim temos acesso aos seus sentimentos e às suas emoções: 


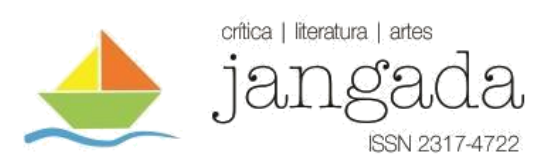

Vi minha percepção distorcer. Corri pra frente do espelho, meu rosto parecia desfigurado, achei que estivesse tendo um derrame. Misturou todos os meus temores, essa notícia me... Não gosto de lembrar. O deputado fez uma pausa e chorou. Desculpe. Me emocionei. Esse menino provavelmente passou pelo processo que eu e tantos outros passamos e passarão. De humilhação, xingamento e insulto. (ABUJAMRA, 2015, p. 37)

A forma de caracterizar o parlamentar, personagem principal da matéria, envia o leitor para um ambiente midiático desde o início com expressões próprias das artes visuais:

Concentração. Câmera. Ação! Poemaria. Cena 1. Take 1. Era sábado de sol e Jean Wyllys estava em um estúdio em São Paulo para gravar uma participação do documentário Poemaria. Aos 41 anos, o parlamentar adotou o cabelo comprido e barba rala que o deixam parecido com Jon Snow, personagem da série Game of Thrones, da qual é fã. Usa um escapulário com as imagens de Jesus Cristo e Nossa Senhora, e uma pulseira de contas de candomblé. Vestia calça jeans e bata banca, decotada o bastante para deixa visível a tatuagem que lhe ocupa todo o peito: "Gente é para brilhar, não para morrer de fome." São versos de um poema de Vladimir Maiakóvski, que Caetano Veloso incluiu numa canção de 1977. "Tem muito a ver com minha vida, comentou." (ABUJAMRA, 2015, p. 34)

A reportagem de Adriana Abujamra evidencia mecanismos de elaboração que a enriquecem ao trazer formas de expressão para além do ato de reportar dos recursos jornalísticos. A reportagem é extensa, com alguns momentos de digressão, e apresenta informações que podem ser consideradas desnecessárias para o leitor familiarizado com os textos jornalísticos exatos e precisos. Significa dizer que nessas duas reportagens aqui mencionadas, "A força muda do meu grito" e "A bancada de um homem só", não são verificados dados muito presentes em matérias do jornalismo diário. Se tomarmos como exemplo outras reportagens referentes ao caso de Marco Archer, publicadas em veículos da imprensa cotidiana, podemos perceber a diferença de escolhas feitas no processo de escrita. Naquelas havia uma insistência no registro de dados supostamente precisos, tais como quantidade de drogas transportadas, tempo de prisão, trâmites jurídicos, datas supostamente precisas. Isso não aparece na matéria publicada na piauí, o que nos faz perceber um tratamento 
diferente no que se elege para construir a narrativa jornalística. Nos dois casos até aqui mostrados, os personagens, suas emoções, e um determinado ponto de vista do narrador construído na matéria parecem ser os elementos mais elaborados pelo jornalista. Os detalhes como a descrição da gestualidade do personagem focalizado (“Olhou para os policiais e fez sinal de que o passaporte estava numa das malas"), o pensamento íntimo acompanhado de uma opinião do narrador ("Sem que o policial percebesse, tomou a decisão mais ousada e improvável: fugir"), o que está sendo usado pelo sujeito em destaque ("Usa um escapulário com as imagens de Jesus Cristo e Nossa Senhora, e uma pulseira de contas de candomblé” ) demonstram e consolidam experiência de escrita de uma narrativa distinta das costumeiras reportagens do cotidiano.

A última reportagem da piauí que será analisada, "O julgamento de Jararaca” (2017), de Adriana Negreiros, conta a história de José Leite de Santana, o Jararaca, soldado de Lampião que foi parar no banco dos réus postumamente.

\section{O JULGAMENTO DE JARARACA}

Um soldado de Lampião no banoo dos réus da história ADRIANA NEGREIROS $f \quad 0$ FIGURA 6 Foto da Tropa de Lampião Fonte: Revista piauí. OCTÁVIO, 1997.

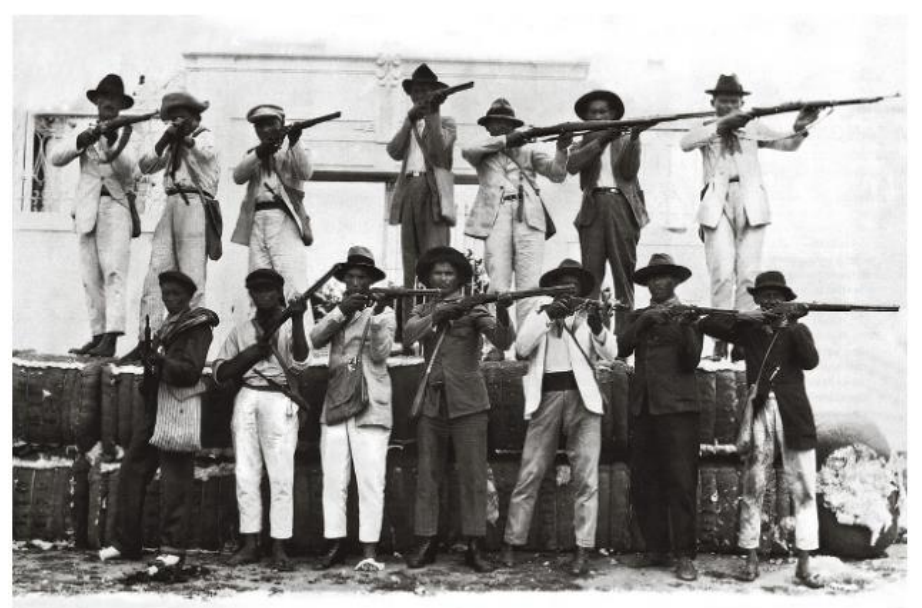

A reportagem foi selecionada por ilustrar, a nosso ver, uma forte tendência da revista piauí: a abordagem de pautas pouco convencionais e ignoradas pela grande mídia. A produção do jornalismo diário tem como ponto de partida um fato recente, novo. Ao abordar pautas atemporais, a revista revela seu espírito híbrido, misturando reportagens "ao estilo new journalism (ou jornalismo literário) com crônicas, perfis e diários de temas preferencialmente nacionais, além de textos ficcionais" (COLOMBO, 2006). O que importa na piauí são histórias curiosas, nas palavras de João Moreira Salles, “contar boas histórias com humor” (PIAUÍ, 2019, Jangada | nr. 16, jun/dez, 2020 | ISSN 2317-4722 
p. 8). A escolha do próprio termo história para nomear os textos publicados na revista mostra que a piauí ultrapassa os limites dos acontecimentos cotidianos, proporcionando visões amplas da realidade, rompendo com as correntes burocráticas do lead, evitando os definidores primários, como afirma Pena (2006, p. 13).

O tratamento dado ao texto sobre Jararaca assemelha-se ao de uma narrativa ficcional, como já verificamos anteriormente nas outras reportagens, que se centram na elaboração do personagem e na demonstração da posição ética do narrador em relação ao fato narrado e ao personagem focalizado. O parágrafo de abertura da matéria de Adriana Negreiros sustenta essa afirmação:

De todas as crueldades atribuídas ao cangaceiro José Leite de Santana, vulgo Jararaca, a mais famosa consistia em arremessar crianças para o alto e aparálas com a ponta do punhal. Trespassados pela lâmina, garotinhos leves o bastante para serem lançados na direção do sol morriam lenta e dolorosamente, em meio aos gritos dos pais - e às gargalhadas do cangaceiro. (NEGREIROS, 2017, p. 30).

De forma aprofundada e sem o caráter efêmero do jornalismo diário, a reportagem de Adriana Negreiros mantém o enfoque imaginativo e, assim como as duas reportagens analisadas anteriormente, conta a história cena a cena, registrando os gestos, os hábitos e as características simbólicas da personagem principal: "além de assassino sádico e cruel, Jararaca - Forte, resistente, ágil, moreno-escuro, atirador exímio, grande lutador de facas" (NEGREIROS, 2017, p. 32). Novamente constatamos que as reportagens da revista piauí, por meio do trabalho com a linguagem e o uso de diferentes formas de narrar, transformam temas não atuais em arranjos linguísticos complexos, fazendo com que a máxima de Salles se confirme: "qualquer assunto bem narrado é um assunto interessante" (SALLES, 2015).

\section{CONSIDERAÇÕES FINAIS}

É possível verificar, nos exemplos aqui destacados, o uso dos recursos defendidos por Wolfe (2005, p. 54) apresentados inicialmente: o interesse de se contar a história cena a cena, em detrimento de uma organização mais cronológica da matéria narrada; a valorização das falas sobre os personagens e dos diálogos da forma realista, de modo a envolver mais o leitor; e a construção clara de um ponto de vista do narrador do fato e o importante apego aos detalhes 


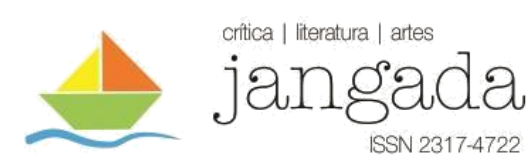

para o registro de gestos, mobílias, roupas, decorações, costumes, cultura, comportamentos, elementos que, de certo modo, tanto confirmam o aspecto cotidiano do fato narrado quanto dá a ele uma importante atemporalidade, muito própria dos textos literários. Essa percepção reforça a afirmação inicial de que na piauí encontramos expressões do jornalismo literário, encontramos o "repórter-escrito", aquele que é capaz de transformar o fato em história, isto é, capaz de realizar "a busca do conteúdo e forma ancorados no real, mas expressos de maneira fascinante quanto as dos melhores textos de ficção" (VILA BOAS, 2007, p. 22). Embora Salles tenha afirmado que os textos da piauí não tentam imitar o estilo dos novos jornalistas, confirmase que essa tendência da escrita jornalística marcou a sua trajetória à frente da revista, pois para ele a tensão narrativa é o fator comum entre os textos.

Por nossos levantamentos pode-se, enfim, afirmar que na piauí, a literatura se faz presente de pelo menos duas formas distintas. Uma delas é a circulação de poemas propriamente ditos, de modo a dar ouvidos a poetas contemporâneos que registram e tensionam o tempo presente. Outro modo de a literatura aparecer é essa forma de escrita da narrativa presente nas reportagens na qual o jornalista procura expressar suas formas de "imersão, humanização, autoria e criatividade" (VILAS BOAS, 2007, p. 21), ao elaborar reportagens capazes de apresentar visões amplas da realidade e, principalmente, garantirem a perenidade e a profundidade aos fatos focalizados e narrados.

\section{REFERÊNCIAS BIBLIOGRÁFICAS}

ABUJAMRA, Adriana. A bancada de um homem só, In: piauí, São Paulo, n. 110, novembro de 2015. Disponível em: <https://piaui.folha.uol.com.br/materia/bancada-de-um-homem-so/>. Acesso em: 15/01/2019.

AGAMBEN, Giorgio. O que é o contemporâneo? e outros ensaios. Tradução de Vinicius Nicastro Honesko. Chapecó, SC: Argos, 2009.

ALEIXO, Ricardo. A Força Muda do Meu Grito. In: piauí, São Paulo, n. 167, agosto de 2020a. Disponível em: <https://piaui.folha.uol.com.br/materia/forca-muda-do-meu-grito/>. Acesso em: 01/09/2020.

ALEIXO, Ricardo. Conforme o acaso. In: piauí, São Paulo, n. 167, agosto de 2020b. Disponível em: <https://piaui.folha.uol.com.br/materia/forca-muda-do-meu-grito/>. Acesso em: 01/09/2020. 


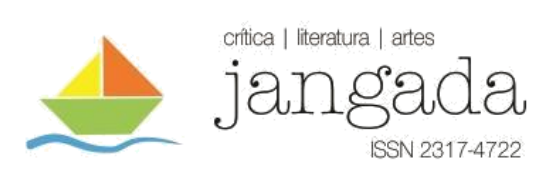

ALEIXO, Ricardo. Minhas coisas favoritas. In: piauí, São Paulo, n. 167, agosto de 2020c. Disponível em: <https://piaui.folha.uol.com.br/materia/forca-muda-do-meu-grito/>. Acesso em: 01/09/2020.

ALEIXO, Ricardo. Quando soa a nossa voz. In: piauí, São Paulo, n. 167, agosto de 2020d. Disponível em: <https://piaui.folha.uol.com.br/materia/forca-muda-do-meu-grito/>. Acesso em: 01/09/2020.

ALEIXO, Ricardo. A Força Muda do Meu Grito. In: piauí, São Paulo, n.167, agosto de 2020e. Disponível em: <https://piaui.folha.uol.com.br/materia/forca-muda-do-meu-grito/>. Acesso em: 01/09/2020.

AMARAL, Luiz. Jornalismo: matéria de primeira página. 4.ed. Rio de Janeiro: Tempo Brasileiro, 1986.

ANJOS, Augusto dos. Eu e Outras Poesias. Rio de Janeiro: Civilização/Itatiaia, 1982.

BARROS, Manoel de. Gramática Expositiva do chão: poesia quase toda. 3. ed. Rio de Janeiro: Civilização Brasileira, 1996.

BARROS, Manoel de. Matéria de Poesia. São Paulo: Leya, 2013.

BANDEIRA, Manuel. Libertinagem \& Estrela da Manhã. 16.ed. Rio de Janeiro, Nova Fronteira, 2000.

BRITO, Orlando. Jean Wyllys, no Congresso. In: piauí, São Paulo, n. 110, novembro de 2015. Disponível em: <https://piaui.folha.uol.com.br/materia/bancada-de-um-homem-so/>. Acesso em: 02/01/2019.

COLOMBO, Sylvia. Jornalismo Literário e Ficção marcam estreia da revista "Piauí". In: Folha de São Paulo. Outubro de 2006. Disponível em: <https://www1.folha.uol.com.br/folha/ilustrada/ult90u64970.shtml>. Acesso em: 10/01/2019. DUVIVIER, Gregório. Ligue os Pontos. In: piauí, São Paulo, n. 85, outubro de 2013. Disponível em: < https://piaui.folha.uol.com.br/materia/ligue-os-pontos/ >. Acesso em: $10 / 09 / 2020$.

FERREIRA, Raquel França dos Santos A “última página de O Cruzeiro: Crônicas e escrita política e Rachel de Queiroz no Pós-64. Tese. (Doutorado) Universidade Federal Fluminente/ Instituto de Ciências Humans e Filosofia Departamento de História, 2015.

FORTUNA, Felipe. Cada um tem seu silêncio. In: piauí, São Paulo, n. 148, janeiro de 2019. Disponível em: <https://piaui.folha.uol.com.br/materia/cada-um-tem-seu-silencio/>. Acesso em: 11/09/2020. 
GALLO, Ricardo. A última viagem. In: piauí, São Paulo, n. 101, fevereiro de 2015. Disponível em: < https://piaui.folha.uol.com.br/materia/a-ultima-viagem/>. Acesso em: 15/01/2019.

GUIMARÃES, Raquel Beatriz Junqueira. Literatura em revista: o caso Manchete. In: Anais do SILEL. Volume 3, Número 1. Uberlândia: EDUFU, 2013.

LIUZZI, Laura. Poemas por Laura Liuzzi. In: piauí, São Paulo, n. 47, agosto de 2010. Disponível em: < https://piaui.folha.uol.com.br/materia/poemas-por-laura-liuzzi/>. Acesso em: 10/09/2020.

LUCAS, Fábio. Apresentação. In: BRITO, José Domingos de (Org.). Mistérios da criação literária. São Paulo: Novera, 2007.

MARQUES, Martins. Noções de Linguística. In: piauí, São Paulo, n. 154, julho de 2019. Disponível em: < https://piaui.folha.uol.com.br/materia/nocoes-de-linguistica/>. Acesso em: $11 / 09 / 2020$.

NEGREIROS, Adriana. Um soldado de Lampião no banco de réus da história. In: piauí, São Paulo, n. 130, julho de 2017. Disponível em: <https://piaui.folha.uol.com.br/materia/ojulgamento-de-jararaca/>. Acesso em: 10/01/2019.

OCTÁVIO, J. Tropa de Lampião. In: piauí, São Paulo, n. 130, julho de 2017. Disponível em: $<$ https://piaui.folha.uol.com.br/materia/o-julgamento-de-jararaca/>. Acesso em: 10/01/2019. PENA, Felipe. Jornalismo literário. São Paulo: Contexto, 2006.

PEREIRA, Edmilson. De volta ao sol. In: piauí, São Paulo, n. 157, outubro de 2019a. Disponível em: < https://piaui.folha.uol.com.br/materia/o-manto-tupinamba-e-um-ninho-naescuridao-do-mundo/ >. Acesso em: 15/09/2020.

PEREIRA, Edmilson. Jam Session. In: piauí, São Paulo, n. 157, outubro de 2019c. Disponível em: <https://piaui.folha.uol.com.br/materia/o-manto-tupinamba-e-um-ninho-na-escuridao-domundo/ >. Acesso em: 15/09/2020.

PEREIRA, Edmilson. Roda-viva. In: piauí, São Paulo, n. 157, outubro de 2019b. Disponível em: <https://piaui.folha.uol.com.br/materia/o-manto-tupinamba-e-um-ninho-na-escuridao-domundo/ >. Acesso em: 15/09/2020.

PEREIRA, Edmilson. Roda-viva. In: piauí, São Paulo, n. 157, outubro de 2019d. Disponível em: <https://piaui.folha.uol.com.br/materia/o-manto-tupinamba-e-um-ninho-na-escuridao-domundo/ >. Acesso em: 15/09/2020.

PIAUÍ. Mídia kit. 2019. Disponível em: <https://piaui.folha.uol.com.br/wpcontent/uploads/2019/04/midiakit2019-v2.pdf>. Acesso em: 10/09/2020. 
REIMÃO, Sandra Lucia Amaral de Assis. Repressão e resistência: censura a livros na ditadura militar. Tese (Livre docência em Comunicação e Cultura) Escola de Artes Ciências e Humanidades da Universidade de São Paulo. 2011.

RITTER, Eduardo. New Journalism: o livre amor entre o jornalismo e a literatura. In: Rizoma, Santa Cruz do Sil, v. 1, n.1, junho de 2013.

ROCHA, Pedro. Breve Antologia da Poesia Engraçada. Organização: Gregório Duvivier. São Paulo: Ubu Editora, 2017.

SALLES, João Moreira. João Moreira Salles fala sobre a revista piauí e evita o jornalismo literário. 2007. Disponível em: <https://www.comunique-se.com.br/> Acesso em: 10/01/2019. SALLES, João Moreira. João Moreira Salles. [Entrevista concedida a Alberto Dines]. In: $O$ Observatório da Imprensa. 2015. Disponível em:

$<$ http://www.observatoriodaimprensa.com.br/oitv/joao-moreira-salles/ $\geq$. Acesso em: 11/08/2019.

SALLES, João Moreira. Sempre um Papo. [Entrevista concedida à TV Câmara]. In: TV Câmara. 2012. Disponível em: <https://www.camara.leg.br/tv/179633-joao-moreira-sallesdocumentarista/>. Acesso em: 11/08/2019.

TENÓRIO, Carlos Alberto. Onde estão os poetas brasileiros? In: Manchete, 29/11/1952. p.1113

VELOSO, Caetano. Alegria, Alegria. São Paulo: Phililips Records, 1968. LP, Faixa 4 $(2 \min 43 s)$.

VILAS BOAS, Sérgio (Org.). Jornalistas literários - narrativas da vida real por novos autores brasileiros. São Paulo: Summus e ABJL, 2007.

WEISE, Fabiane Angélica. Para compreender o jornalismo literário. In: Observatório da Imprensa. 2013. Disponível em:

<http://www.observatoriodaimprensa.com.br/diretorioacademico/_ed730_para_compreender_ o_jornalismo_literario/>. Acesso em: 15/01/2019.

WOLFE, Tom. Radical chique e o novo jornalismo. São Paulo: Companhia das Letras, 2005. 